\title{
Satisfaction Assessment among Type 2 Diabetic Patients at Tanta University Hospitals, Egypt
}

\author{
Eman Ali Younis ${ }^{1 *}$, Nessreen Ahmed Kotb ${ }^{2}$, Ali Ali Elsherbiny ${ }^{1}$, \\ Abdel Aziz Farouk El Dieb ${ }^{1}$ and Nehalsalah Shehab ${ }^{1}$
}

\author{
${ }^{1}$ Public Health and Community Medicine, Faculty of Medicine Tanta University, Egypt \\ ${ }^{2}$ Internal medicine, Faculty of Medicine Tanta University, Egypt
}

*Corresponding author

\section{A B S T R A C T}

\section{Keywords \\ Diabetes, Type 2, \\ Quality, \\ Satisfaction}

Article Info

Accepted:

06 September 2018

Available Online:

10 October 2018
Diabetes mellitus is a major contributor to morbidity and mortality worldwide. Identification of patient requests, needs and judgment on health care received is the starting point of patients centered approach; therefore patient satisfaction is considered as important measure to evaluate the quality of health services and can predict both compliance and utilization that associated with the continuity of care. 1. Assess type 2 diabetic patients' satisfaction with the provided care at Tanta University Hospitals. This study was cross sectional one carried-out in the internal medicine hospital at Tanta University Hospital. The study subjects included; 245 admitted type 2 diabetic patients. Tools of the study; A validated patient satisfaction questionnaire -18 was used to assess the satisfaction with the provided care. The majority of the studied patients were satisfied regarding general satisfaction and time spent with doctor subscale, more than three quarters were satisfied regarding technical quality and accessibility subscale, most of the studied patients $(91.8 \%)$ were satisfied regarding interpersonal manner, and less than two thirds $(62.4 \%)$ were satisfied regarding communication. As regard financial aspects, only $35.5 \%$ were satisfied. The total satisfaction level among the studied patients was high.

\section{Introduction}

Diabetes mellitus (DM) is one of the major non- communicable diseases with a dramatically increasing prevalence in both the developed and the developing world. The Middle East region has seen some of the largest growth in DM in the world; five out of the top 10 countries with the highest diabetes prevalence are in the Middle East region, and trends predict that the region will see over
$90 \%$ growth in the disease by 2030 . These perturbing trends are a result of the dramatic changes in dietary and lifestyle habits in this rapidly economically developing region (Bener, Al- Hamaq et al., 2014).

In the Middle East and North Africa (Mena) region, almost 37 million people have diabetes and are expected to rise to 68 million by the year 2035. It was estimated that 1 in 10 adults have diabetes and that diabetes was expected 
to cause 363,000 deaths in 2014. Fifty-three percent of those deaths will be under the age of 60 years (Ahmad, Elnour et al., 2015).

Christian Bommer and colleagues reported that the cost of diabetes worldwide was US $\$ 1.31$ trillion, or $1.8 \%$ of the global gross domestic product (GDP), in 2015. Their study of the global economic burden of diabetes showed that two thirds of these total costs were direct medical costs ( $\$ 857$ billion) and one third were indirect costs, such as lost productivity (Zhang and Gregg, 2017).

Quality assessment in chronic disease has become increasingly widespread, with published quality measurement sets in conditions as diverse as diabetes, cardiac diseases, stroke, and cancer. The criteria for selecting conditions for quality assessment include mortality and morbidity burden, variation in care (performance gaps), and the evidence for effective care (process-outcome link) (Kanwal 2014).

Patients' satisfaction is considered an important source of information about the quality of care as a consumer assessment and it has been shown to be associated with positive outcomes, reduced disease cost and better health. It reflects the health plans, health systems and the process of care. Emphasizing the role of the patients and their rights to be exposed to information and treatment plans are important elements of quality of care. Patient satisfaction regarding diabetes services is indirectly used to assess the quality of the health care system (Balla, Shaaban et al., 2016).

\section{Subject and Methods}

A cross-sectional study was carried-out in the Internal Medicine Hospital (endocrinology unit) at Tanta University Hospital (TUH). This hospital is a teaching and referral hospital providing health services to the population of Tanta and other neighboring rural and urban areas. Personal interview with the selected admitted type 2 diabetes patients who admitted to T.U.H during the study period to assess their satisfaction. Patients were eligible for inclusion if they were aged $\geq 18$ years, had a history of at least one visit for follow up at outpatient clinic of Tanta University Hospitals in the last year and who had been diagnosed for type 2 diabetes for 1 year and more. Exclusion criteria were; cases with duration of onset of diabetes less than one year, age less than 18 years, gestational diabetes cases, cases with no history of follow up in the outpatient clinic of T.U.H, and type1diabetes.

The sample of this study was a purposive one. The sample size was calculated using Mini tab statistical program version 16 . The minimum sample size was calculated for single proportion of uncontrolled diabetes to be 245 file during one year duration putting into consideration that the power of the test was $95 \%$, comparative probability $38.6 \%$ (for uncontrolled diabetes) (Elaziz, Nour-Eldin et al., 2014) and hypothesed probability from pretest study $50 \%$ (10 files out of 20).

\section{Tools of the study}

A validated patient satisfaction questionnaire 18 was used to assess the satisfaction with the provided care by using the Arabic version and revalidation was done by making double translation of the questionaire.

\section{Statistical design}

Data was presented and statistically analyzed by using SPSS-V19 (statistical package for social version 19). Numerical data was presented as mean and standard deviation (SD) and categorical data was presented as number and percentage. Chi-squared test was used for statistical analysis. When the chi- 
squared test was not appropriate, the likelihood ratio test was applied. The level of significance was adopted at $\mathrm{p}<0.05$.

\section{Ethical consideration}

Ethical considerations of the study were carried out according to that of the ethical committee of Tanta Faculty of Medicine and written consent was obtained from every patient.

\section{Results and Discussion}

The patients ages ranged from 31-72years with mean of 53.1+9.4 years. More than twothirds $(70.6 \%)$ were females and more than four fifths $(82.1 \%)$ were illiterate and primary educated. About one fifth (20.8\%) of them were working as daily labors (Table 1). The duration of diabetes since diagnosis ranged from 1-30 years with mean of $12+7.5$ years, $75.5 \%$ were treated by insulin and 18 $\%$ were treated by oral hypoglycemics plus insulin and three-quarters (74.3\%) of them had one monthly follow-up visit and $19.2 \%$ had one visit every two months. The most common complications among them were neuropathy followed by retinopathy and diabetic foot $(86.9 \%, 56.3 \%$ and $31 \%$ respectively). More than two-thirds of the patients (67.8\%) were hypertensive. About one eighth (12.7\%) were currently smokers (Table 2).

Slightly more than four fifths $(80.4 \%)$ were satisfied regarding general satisfaction subscale, more than three quarters $(77.1 \%)$ were satisfied regarding technical quality, most of the studied patients $(91.8 \%)$ were satisfied regarding interpersonal manner, and less than two thirds (62.4\%) were satisfied regarding communication. As regard financial aspects, only $35.5 \%$ were satisfied. Under time spent with doctor and accessibility subscales, more than four fifths $(85.3 \%)$ and $78.8 \%$ were satisfied respectively (Table 3).
Statistically significant relationship between age and the total satisfaction level $(\mathrm{P}=0.003)$, as satisfaction level was $97.2 \%$ among the older age group compared to $83.3 \%$ among the younger age group. Also statistically significant relationships were detected between gender and educational level from one side and the total satisfaction level from the other side $(\mathrm{P}=0.009$ and 0.014) respectively. Most of females $(93.1 \%)$ were satisfied compared to $88.9 \%$ for males and satisfaction was highest (97\%) among illiterate patients (Table 4). Most of uncontrolled patients had higher satisfaction level compared to controlled patients with statistically significant relationships between all the outcome measures and total satisfaction level of the studied diabetic patients. Regarding glycemic control; $94.4 \%$ of uncontrolled patients were satisfied compared to $80.0 \%$ among controlled patients. The same results were attained for all the outcome measures (Table 5).

The current study showed a high level of the overall patient satisfaction (91.8\%) (Table 3). In agreement, Ghazwani et al., (2014) in Saudi Arabia reported that, $87 \%$ of the studied diabetic patients were satisfied (Ghazwani and Al Jaber 2014). Other studies by Othman et al., in Dubai (2015), Allan in Australia (2009), AL Eisa et al., in Kuwait (2005), and Gad Allah et al., in Egypt (2003) reported that the overall patient satisfaction ranged between 98\% and 99.6\% (Gadallah, Zaki et al., 2003, Al-Eisa, Al-Mutar et al., 2005, Allan, Schattner et al., 2009, Othman, Hussein et al., 2015). While Al Emadi et al., in Qatar (2009) and AL Faris et al., in Saudi Arabia (1996) reported lower overall patients' satisfaction $75.2 \%$ and $64.2 \%$ respectively (Al-Faris, Khoja et al., 1996, Al Emadi, Falamarzi et al., 2009).

This high level of patients' satisfaction in the present study mostly explained by; patients were not concerned about the quality of their 
doctors' technical skills and the majority of the patients responded favorably to most items of the questionnaire saying "all people in the unit are good", mentioned that their satisfaction is related to the behavior of doctors and nurses rather than their concern about the relief from pain and solution to their medical problems.

Considering patient satisfaction subscales, the current study showed, the interpersonal manner had the highest satisfaction score (91.8\%) (Table 3). In agreement, Margolis et al., in UAE (2003) found humanness domain got the highest score in the domains of satisfaction (Margolis, Al-Marzouqi et al., 2003).

Similarly, Othman et al., in Dubai (2015) found that humanness of the staff subscale of satisfaction got high score (99.25\%) (Othman, Hussein et al., 2015).

The current study revealed that, time spent with doctor also had high satisfaction score (85.3\%) (Table 3). Peyrot et al., (2006) studied patient and provider perceptions of care for diabetes in a multicenter study from Asia, Australia, Europe and North America and reported that, time spent with doctor was rated high by patients in all countries (Peyrot, Rubin et al., 2006).

Accessibility is one of the principles of health for all, as stated in the Alma Ata declaration on primary health care in (1978). It has been reported that accessibility is the strongest predictor of overall satisfaction with quality of health care (Yingtaweesak, Yoshida et al., 2013).

The current study revealed that more than three quarters of patients $(78.8 \%)$ were satisfied with the accessibility of the services (Table 3). This was in concordance with Peyrot et al., (2006) who reported in his study that, patient-reported ease of access to providers was rated high (mean $=77 \%$, range $=65 \%-84 \%$ ), with Scandinavia and the Netherlands rated significantly lower than the overall mean while Australia and France were rated significantly higher (Peyrot, Rubin et al., 2006).

While in Qatar a study done by Al Emadi et al., (2009) reported that accessibility of the services got the highest score on domains of satisfaction (Al Emadi, Falamarzi et al., 2009). Another study in Dubai (2015) also reported very high level of satisfaction (95.29\%) regarding the accessibility (Hussein 2015).

The present study also reported that, more than three quarters $(77.1 \%)$ were satisfied with technical quality (Table 3). In contrast to present result, Othman et al., in Dubai (2015) found that, the effectiveness of service got the highest score $(99.63 \%+1.55)$ (Othman, Hussein et al., 2015). The least scores in the current study were recorded for financial aspect of the care and communication $(35.5 \%$ and $62.4 \%$ respectively) this may be due to low socio economic status of the study subjects for the first subscale.

Some problems were encountered by patients such as difficulties in; follow up with same physician each time, referring system as well as difficulties if the patient missed the appointment (no call back from the clinic).

Peyrot et al., (2006) studied patient and provider perceptions of care for diabetes in a multicenter study and found that Patientreported financial barriers to care varied across nations (mean $=26 \%$, range $=9 \%-64 \%$ ), with several European Union countries having significantly lower financial barriers and the USA, Poland and India having significantly higher financial barriers (Peyrot, Rubin et al., 2006). 
Table.1 Socio-demographic characteristics of the studied diabetic patients

\begin{tabular}{|c|c|c|}
\hline \multirow[t]{2}{*}{ Socio-demographic data } & \multicolumn{2}{|c|}{ Studied diabetic patients $(\mathrm{N}=\mathbf{2 4 5})$} \\
\hline & $\mathbf{N}$ & $\%$ \\
\hline \multicolumn{3}{|l|}{ Age (years): } \\
\hline$(30-<40)$ & 24 & 9.8 \\
\hline$(40-<50)$ & 78 & 31.8 \\
\hline$(50-<60)$ & 100 & 40.8 \\
\hline$(60-)$ & 43 & 17.6 \\
\hline Range & \multicolumn{2}{|c|}{$31-72$} \\
\hline Mean \pm SD & \multicolumn{2}{|c|}{$53.1+9.4$} \\
\hline \multicolumn{3}{|l|}{ Gender: } \\
\hline Female & 173 & 70.6 \\
\hline Male & 72 & 29.4 \\
\hline \multicolumn{3}{|l|}{ Educational level: } \\
\hline Illiterate & 133 & 54.3 \\
\hline Primary & 68 & 27.8 \\
\hline Secondary & 32 & 13.1 \\
\hline University & 12 & 4.8 \\
\hline \multicolumn{3}{|l|}{ Employment: } \\
\hline Daily labor & 51 & 20.8 \\
\hline Not working/ house wife & 194 & 79.2 \\
\hline
\end{tabular}


Table.2 Diabetic and smoking history of studied diabetic patients

\begin{tabular}{|c|c|c|}
\hline \multirow[t]{2}{*}{ Diabetic and smoking history } & \multicolumn{2}{|c|}{ Studied diabetic patients $(\mathrm{N}=\mathbf{2 4 5})$} \\
\hline & $\mathbf{n}$ & $\%$ \\
\hline \multicolumn{3}{|l|}{ Duration since diagnosis (years): } \\
\hline$(1-<5 y)$ & 59 & 24.1 \\
\hline$(5-10 y)$ & 71 & 29.0 \\
\hline$(>10 \mathrm{y})$ & 115 & 46.9 \\
\hline Range & \multicolumn{2}{|c|}{$1-30$} \\
\hline Mean + SD & \multicolumn{2}{|c|}{$12 \pm 7.5$} \\
\hline Median & \multicolumn{2}{|c|}{10} \\
\hline \multicolumn{3}{|l|}{ Type of treatment: } \\
\hline Oral hypoglycemic drugs & 16 & 6.5 \\
\hline Oral plus insulin & 44 & 18.0 \\
\hline Insulin & 185 & 75.5 \\
\hline ACEIs/ ARBs & 91 & 37.1 \\
\hline Statin/lipid control & 128 & 52.2 \\
\hline ASA/antiplatelet & 75 & 30.6 \\
\hline \multicolumn{3}{|l|}{ Compliance with antidiabetic treatment: } \\
\hline Yes & 162 & 66.1 \\
\hline To some extent & 83 & 33.9 \\
\hline \multicolumn{3}{|l|}{ Frequency of follow-up visits: } \\
\hline Weekly & 8 & 3.3 \\
\hline Twice monthly & 8 & 3.3 \\
\hline Monthly & 182 & 74.3 \\
\hline Every 2 months & 47 & 19.1 \\
\hline \multicolumn{3}{|l|}{ Complication: ${ }^{\mathrm{a}}$} \\
\hline Neuropathy & 213 & 86.9 \\
\hline Nephropathy & 52 & 21.2 \\
\hline Retinopathy & 138 & 56.3 \\
\hline Diabetic foot & 76 & 31.0 \\
\hline Co-morbidity:(Hypertension) & 166 & 67.8 \\
\hline \multicolumn{3}{|l|}{ Previous admission: } \\
\hline No & 103 & 42.0 \\
\hline Yes & 142 & 58.0 \\
\hline \multicolumn{3}{|l|}{ Cigarette smoking: } \\
\hline Non smokers & 199 & 81.2 \\
\hline Ex-smokers & 15 & 6.1 \\
\hline Currently smokers & 31 & 12.7 \\
\hline
\end{tabular}

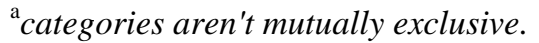

(ACEIs): angiotensin converting enzyme inhibitors/ (ARBs) angiotensin receptor blockers \{antihypertensive\} (ASA): Acetyl salicylic acid

N.B: diet therapy was not presented among the studied patients. 
Table.3 Total satisfaction level and its main subscales among studied diabetic patients

\begin{tabular}{|c|c|c|c|c|c|c|}
\hline \multirow[t]{3}{*}{ Satisfaction subscales } & \multicolumn{6}{|c|}{ Satisfaction level $(\mathrm{N}=\mathbf{2 4 5})$} \\
\hline & \multicolumn{2}{|c|}{ Dissatisfied } & \multicolumn{2}{|c|}{ Neutral } & \multicolumn{2}{|c|}{ Satisfied } \\
\hline & $\mathbf{n}$ & $\%$ & $\mathbf{n}$ & $\%$ & $\mathbf{n}$ & $\%$ \\
\hline General satisfaction & 12 & 4.9 & 36 & 14.7 & 197 & 80.4 \\
\hline Technical quality & 32 & 13.1 & 24 & 9.8 & 189 & 77.1 \\
\hline Interpersonal manner & 8 & 3.3 & 12 & 4.9 & 225 & 91.8 \\
\hline Communication & 8 & 3.3 & 84 & 34.3 & 153 & 62.4 \\
\hline Financial aspects & 48 & 19.6 & 110 & 44.9 & 87 & 35.5 \\
\hline Time spent with doctor & 20 & 8.2 & 16 & 6.5 & 209 & 85.3 \\
\hline Accessibility and convenience & 28 & 11.4 & 24 & 9.8 & 193 & 78.8 \\
\hline Total satisfaction & 16 & 6.5 & 4 & 1.6 & 225 & 91.8 \\
\hline
\end{tabular}

Table.4 Relationship between total satisfaction level and socio-demographic characteristic of studied diabetic patients

\begin{tabular}{|c|c|c|c|c|c|c|c|}
\hline \multirow[t]{3}{*}{ Socio-demographic data } & \multicolumn{7}{|c|}{ Total satisfaction level of studied diabetic patients $(\mathrm{N}=\mathbf{2 4 5})$} \\
\hline & \multicolumn{2}{|c|}{$\begin{array}{l}\text { Dissatisfied } \\
\quad(n=16)\end{array}$} & \multicolumn{2}{|c|}{$\begin{array}{c}\text { Neutral } \\
(n=4)\end{array}$} & \multicolumn{2}{|c|}{$\begin{array}{c}\text { Satisfied } \\
(n=225)\end{array}$} & \multirow[t]{2}{*}{$\begin{array}{c}\text { MCET** } \\
\mathbf{P}\end{array}$} \\
\hline & $\mathbf{n}$ & $\%$ & $\mathbf{n}$ & $\%$ & $\mathbf{n}$ & $\%$ & \\
\hline Age (years): & & & & & & & $.003 *$ \\
\hline$(30-<40)$ & 4 & 16.7 & 0 & 0.0 & 20 & 83.3 & \\
\hline$(40-<50)$ & 8 & 10.3 & 4 & 5.1 & 66 & 84.6 & \\
\hline$(\geq 50-)$ & 4 & 2.8 & 0 & 0.0 & 139 & 97.2 & \\
\hline Gender: & & & & & & & $.009 *$ \\
\hline Female & 12 & 6.9 & 0 & 0.0 & 161 & 93.1 & \\
\hline Male & 4 & 5.6 & 4 & 5.6 & 64 & 88.9 & \\
\hline Educational level: & & & & & & & $.014 *$ \\
\hline Illiterate & 4 & 3.0 & 0 & 0.0 & 129 & 97.0 & \\
\hline Primary & 8 & 11.8 & 4 & 5.9 & 56 & 82.4 & \\
\hline Secondary/University & 4 & 9.1 & 0 & 0.0 & 40 & 90.9 & \\
\hline Employment: & & & & & & & .686 \\
\hline Daily labor & 0 & 0.0 & 0 & 0.0 & 12 & 100.0 & \\
\hline Not working/ house wife & 16 & 6.9 & 4 & 1.7 & 213 & 91.4 & \\
\hline
\end{tabular}

**MCET: montcarlo exact test

*Significant $(P \leq 0.05)$. 
Table.5 Relationship between total satisfaction level and outcome of studied diabetic patients

\begin{tabular}{|c|c|c|c|c|c|c|c|}
\hline \multirow[t]{3}{*}{ Outcome } & \multicolumn{7}{|c|}{ Total satisfaction level of studied diabetic patients $(\mathrm{N}=245)$} \\
\hline & \multicolumn{2}{|c|}{$\begin{array}{l}\text { Dissatisfied } \\
\quad(n=16)\end{array}$} & \multicolumn{2}{|c|}{$\begin{array}{c}\text { Neutral } \\
(n=4)\end{array}$} & \multicolumn{2}{|c|}{$\begin{array}{c}\text { Satisfied } \\
(\mathrm{n}=225)\end{array}$} & \multirow[t]{2}{*}{$\begin{array}{c}\text { MCET** } \\
\mathbf{P}\end{array}$} \\
\hline & $\mathbf{n}$ & $\%$ & $\mathbf{n}$ & $\%$ & $\mathbf{n}$ & $\%$ & \\
\hline Last glycemic control: & & & & & & & \multirow[t]{4}{*}{$.002 *$} \\
\hline Controlled (A1C<6.5g/dl) & 8 & 20.0 & 0 & 0.0 & 32 & 80.0 & \\
\hline Inadequate control(A1C6.5-<9.5g/dl) & 4 & 3.6 & 4 & 3.6 & 102 & 92.7 & \\
\hline Poor control(AIC>9.5g/dl) & 4 & 5.6 & 0 & 0.0 & 67 & 94.4 & \\
\hline \multicolumn{7}{|l|}{ Last systolic blood pressure: } & \multirow[t]{3}{*}{$.007 *$} \\
\hline Controlled (<130mmhg) & 12 & 10.1 & 0 & 0.0 & 107 & 89.9 & \\
\hline Uncontrolled( $(\geq 130 \mathrm{mmhg})$ & 4 & 3.2 & 4 & 3.2 & 118 & 93.7 & \\
\hline \multicolumn{7}{|l|}{ Last diastolic blood pressure } & \multirow[t]{3}{*}{$.023 *$} \\
\hline Controlled( $<80 \mathrm{mmhg})$ & 11 & 9.6 & 0 & 0.0 & 104 & 90.4 & \\
\hline Uncontrolled( $\geq 80 \mathrm{mmhg})$ & 5 & 3.8 & 4 & 3.1 & 121 & 93.1 & \\
\hline \multicolumn{7}{|l|}{ Lipid profile: } & \multirow{5}{*}{$.005^{*}$} \\
\hline Last blood cholesterol & & & & & & & \\
\hline Controlled(<200mg/dl) & 12 & 11.2 & 0 & 0.0 & 95 & 88.8 & \\
\hline Uncontrolled( $>200 \mathrm{mg} / \mathrm{dl})$ & 4 & 2.9 & 4 & 2.9 & 130 & 94.2 & \\
\hline \multicolumn{7}{|l|}{ Last triglycerides } & \\
\hline Controlled(<150mg/dl) & 12 & 10.8 & 0 & 0.0 & 99 & 89.2 & \multirow{2}{*}{$.004 *$} \\
\hline Uncontrolled(>150mg/dl) & 4 & 3.0 & 4 & 3.0 & 126 & 94.0 & \\
\hline
\end{tabular}

**MCET: montcarlo exact test

*Significant $(P \leq 0.05)$.

The current study revealed that, significantly the older ages were more satisfied than younger ones $(97.2 \%$ versus $83.3 \%)$ (Table 4). In agreement, Saeed et al., (2001), Margolis et al., (2003), AL Eisa et al., (2005), Quintana et al., (2006), AL Emadi et al., (2009), and Rahmqvist et al., (2010) found the same results (Saeed, Mohammed et al., 2001, Margolis, AlMarzouqi et al., 2003, Al-Eisa, Al-Mutar et al., 2005, Quintana, González et al., 2006, Al Emadi, Falamarzi et al., 2009, Rahmqvist and Bara 2010). This finding can be explained as older patient are becoming more familiar with the potential shortcomings in the care delivery system and expecting no more from the current situation with consequent fair satisfaction. However, Bener, et al., (2014) in Qatar detected that, significantly younger patients were more satisfied than older ones (Bener, Al- Hamaq et al., 2014). Other studies reported no association between age and satisfaction (Baker and Streatfield, 1995; Qatari and Haran, 1999; Alazri and Neal, 2003; Jalil, Zakar et al., 2017). In the present study, females were more satisfied than males (93.1\% versus $88.9 \%$ ) with statistically significant difference (Table 4). This finding seems to be similar to Hargraves et al., (2001), Bu- Alayyan et al., (2008) and Jalil et al., (2017) (Hargraves, Wilson et al., 2001, Bu-Alayyan, Mostafa et al., 2008, Jalil, Zakar et al., 2017). In contrast other studies showed more significant satisfaction among males (AlEisa, Al-Mutar et al., 2005, Al-Azmi, Mohammed et al., 2006, Al-Sakkak, AlNowaiser et al., 2008). On the other hand, several studies showed no association between overall satisfaction and gender (Baker and Streatfield 1995; Weisman, Henderson et al., 2001; Alazri and Neal 2003, Bener, Al- Hamaq et al., 2014). 
The present study showed that, less educated patients were significantly more satisfied than high educated patients $(97.0 \%$ versus $90.9 \%)$ (Table 4). This finding was consistent with the results seen by Jalil et al., (2017) in Pakistan (Jalil, Zakar et al., 2017) and many other studies (Maq, Elzubier et al., 1997; BabićBanaszak, Kovačić et al., 2001; Niakas, Gnardellis et al., 2004). However, Saeed et al., (2001) showed the opposite results(Saeed, Mohammed et al., 2001). Gadallah et al., (2003) in Egypt and Bener et al., (2014) in Qatar showed that no significant relationship although highly educated patients had a higher satisfaction score compared with less educated patients (Gadallah, Zaki et al., 2003, Bener, Al- Hamaq et al., 2014).

The current study revealed that the satisfaction was none significantly higher among working patients than non-workers (Table 4). This finding was in accordance with $\mathrm{Al}$ Eisa et al., (2005) in Kuwait and Quintana et al., (2006) (Al-Eisa, Al-Mutar et al., 2005, Quintana, González et al., 2006). In contrast, Bener et al., (2014) in Qatar found that diabetic patients who had professional jobs were significantly more satisfied than their counterparts(Bener, Al- Hamaq et al., 2014). This could be attributed to patients who had professional jobs had higher income than none workers which enable them to be more committed to physicians' medical requests. However, Jalil et al., (2017) in Pakistan reported that, unemployed patients were significantly high satisfied than the employed patients (Jalil, Zakar et al., 2017).

The relation between satisfaction and outcome of care measures is complex and there is growing evidence linking patient satisfaction with better medical outcome of care. These outcomes include better compliance, and adherence to medical regimens. However, it is equally true that people who receive both good process and good outcome of care are likely to be more satisfied (Hussein 2015). The current study result showed significant association between the uncontrolled diabetes, uncontrolled blood pressure and uncontrolled lipid profile from one side and patient satisfaction from the other side (Table 5).

In contrary, Boels et al., (2017) studied patient satisfaction in a multicenter study in eight European countries and found that patients with uncontrolled $\mathrm{HbA1c}$ levels were significantly associated with lower satisfaction (Boels, Vos et al., 2017).

Also, Bener et al., (2014) in Qatar found that patients with optimum level of $\mathrm{HbA1C}$, total blood cholesterol, triglycerides and blood pressure were significantly more satisfied (Bener, Al- Hamaq et al., 2014). Redekop et al., (2002) in Dutch and Alazri et al., (2003) found that poorly controlled diabetic patients were being less satisfied (Redekop, Koopmanschap et al., 2002, Alazri and Neal 2003). However Al Shahrani and Baraja (2014) in Saudi Arabia found no association between patient satisfaction and HbA1C control (Al Shahrani and Baraja 2014).

However, the difference between the current study and other studies done in that field may be the studied patients were more concerned about the process and quality of the delivered care than the outcome of their illness.

Based on the results of the present study, we can conclude that;

The total satisfaction level among the studied patients was high.

Quality of health care for diabetic patients was also suboptimal.

Glycemic, lipid and hypertension controls among diabetic patients at Tanta university hospitals were below the recommended standards.

\section{Acknowledgment}

The researcher likes to thank all patients who accepted to participate on the study. 


\section{Declaration}

This research did not receive any specific grant from funding agencies in the public, commercial, or not-for-profit sectors and all costs were paid by the researcher

\section{References}

Ahmad, A. D., et al., (2015). "Pharmacist's interventions to improve clinical outcomes in patients with type 2 diabetes mellitus: Nyala City, South Darfur State, Sudan." International Journal of Diabetes in Developing Countries 35(4): 578-587.

Al-Azmi, S. F., et al., (2006). "Patients' satisfaction with primary health care in Kuwait after electronic medical record implementation." J Egypt Public Health Assoc 81(5\&6): 278-300.

Al-Eisa, I. S., et al., (2005). "Patients' satisfaction with primary health care services at capital health region, Kuwait." Middle East Journal of Family Medicine 3(3): 10-16.

Al-Faris, E. A., et al., (1996). "Patients' satisfaction with accessibility and services offered in Riyadh health centers." Saudi medical journal 17(1): 11-17.

Al-Sakkak, M. A., et al., (2008). "Patient satisfaction with primary health care services in Riyadh." Saudi medical journal 29(3): 432-436.

Al Emadi, N., et al., (2009). "Patients' satisfaction with primary health care services in Qatar." Middle East Journal of Family Medicine 7(9): 4-9.

Al Shahrani, A. and M. Baraja (2014). "Patient satisfaction and it's relation to diabetic control in a primary care setting." Journal of family medicine and primary care 3(1): 5.

Alazri, M. and R. Neal (2003). "The association between satisfaction with services provided in primary care and outcomes in Type 2 diabetes mellitus." Diabetic Medicine 20(6): 486-490.
Allan, J., et al., (2009). "Does patient satisfaction of general practice change over a decade?" BMC family practice 10(1): 13 .

Babić-Banaszak, A.,et al., (2001). "The Croatian Health Survey-Patient's Satisfaction with Medical Service in Primary Health Care in Croatia." Collegium antropologicum 25(2): 449458.

Baker, R. and J. Streatfield (1995). "What type of general practice do patients prefer? Exploration of practice characteristics influencing patient satisfaction." $\mathrm{Br} \mathrm{j}$ gen pract 45(401): 654-659.

Balla, S. A., et al., (2016). "Satisfaction with Diabetes Services at Primary Care Level, Khartoum State, Sudan." American Journal of Health Research 4(5): 127-133.

Bener, A., et al., (2014). "Relationship between patient satisfactions with diabetes care and treatment." Nigerian journal of clinical practice $17(2)$ : 218-225.

Boels, A. M., et al., (2017). "What determines treatment satisfaction of patients with type 2 diabetes on insulin therapy? An observational study in eight European countries." BMJ open 7(7): e016180.

Bu-Alayyan, S., et al., (2008). "Patient satisfaction with primary health care services in Kuwait." Kuwait medical journal 40(1): 25-30.

Elaziz, K. M. A., et al., (2014). "Assessment of Health related Quality of life among diabetics patients in $\mathrm{Al}$ Gharbia Governorate, Egypt using COOP/WONCA charts." Egyptian Journal of Community Medicine 32(3).

Gadallah, M., et al., (2003). "Patient satisfaction with primary health care services in two districts in Lower and Upper Egypt."

Ghazwani, E. Y. and O. A. Al Jaber (2014). "Study of satisfaction of diabetic patients attending the diabetic clinic at primary health centers in Abha city, Saudi Arabia."

Hargraves, J. L., et al., (2001). "Adjusting for patient characteristics when analyzing 
reports from patients about hospital care." Medical care 39(6): 635-641.

Hussein, H. (2015). "Predictors of patient satisfaction among diabetic population attending primary health care centers at Dubai health authority." Quality in Primary Care 23(4).

Jalil, A., et al., (2017). "Patient satisfaction with doctor-patient interactions: a mixed methods study among diabetes mellitus patients in Pakistan." BMC health services research 17(1): 155 .

Kanwal, F. (2014). "Quality of care assessment in chronic liver disease." Clinical Liver Disease 4(6): 149-152.

Maq, Y., et al., (1997). "Satisfaction with health care among primary health care centers attendees' in Al-Khobar, Saudi Arabia." Saudi medical journal 18(3): 227-230.

Margolis, S. A., et al., (2003). "Patient satisfaction with primary health care services in the United Arab Emirates." International journal for quality in health care 15(3): 241-249.

Niakas, D., et al., (2004). "Is there a problem with quality in the Greek hospital sector? Preliminary results from a patient satisfaction survey." Health Services Management Research 17(1): 62-69.

Othman, Z., et al., (2015). "Characteristics of Care Provided to Patients with diabetes Mellitus Attending Primary Health Care Services at Dubai Health Authority." Quality in Primary Care 23(3).

Peyrot, M., et al., (2006). "Patient and provider perceptions of care for diabetes: results of the cross-national DAWN Study." Diabetologia 49(2): 279-288.
Qatari, G. and D. Haran (1999). "Determinants of users' satisfaction with primary health care settings and services in Saudi Arabia." International Journal for Quality in Health Care 11(6): 523-531.

Quintana, J. M., et al., (2006). "Predictors of patient satisfaction with hospital health care." BMC health services research 6(1): 102.

Rahmqvist, M. and A.-C. Bara (2010). "Patient characteristics and quality dimensions related to patient satisfaction." International Journal for Quality in Health Care 22(2): 86-92.

Redekop, W. K., et al., (2002). "Health-related quality of life and treatment satisfaction in Dutch patients with type 2 diabetes." Diabetes care 25(3): 458-463.

Saeed, A. A., et al., (2001). "Satisfaction and correlates of patients' satisfaction with physicians' services in primary health care centers." Saudi medical journal 22(3): 262-267.

Weisman, C. S., et al., (2001). "Gender and patient satisfaction in managed care plans: analysis of the 1999 HEDIS/CAHPS 2.0 H Adult Survey." Women's Health Issues 11(5): 401-415.

Yingtaweesak, T., et al., (2013). "Accessibility of health care service in Thasongyang, Tak Province, Thailand." Nagoya journal of medical science 75(3-4): 243.

Zhang, P. and E. Gregg (2017). "Global economic burden of diabetes and its implications." The Lancet Diabetes \& Endocrinology.

\section{How to cite this article:}

Eman Ali Younis, Nessreen Ahmed Kotb, Ali Ali Elsherbiny, Abdel Aziz Farouk El Dieb and Nehalsalah Shehab. 2018. Satisfaction Assessment among Type 2 Diabetic Patients at Tanta University Hospitals, Egypt. Int.J.Curr.Microbiol.App.Sci. 7(10): 850-860. doi: https://doi.org/10.20546/ijcmas.2018.710.094 